\title{
Prediction of the Likelihood of Households Food Security in the Lake Victoria Region of Kenya
}

\author{
Peter Nyamuhanga Mwita \\ Department of Statistics and Actuarial Sciences \\ Jomo Kenyatta University of Agriculture and Technology, Kenya \\ peter_mwita@yahoo.com \\ Romanus Odhiambo Otieno \\ Department of Statistics and Actuarial Sciences \\ Jomo Kenyatta University of Agriculture and Technology, Kenya \\ rodhiambo@fsc.jkuat.ac.ke \\ Verdiana Grace Masanja \\ Department of Applied Mathematics \\ University of Dar-Es-salaam, Tanzania \\ vmasanja@gmail.com \\ Charles Muyanja \\ Department of Food Science and Technology \\ Makerere University, Uganda \\ ckmuyanja@yahoo.co.uk
}

\begin{abstract}
This paper considers the modeling and prediction of households food security status using a sample of households in the Lake Victoria region of Kenya. A priori expected food security factors and their measurements are given. A binary logistic regression model derived was fitted to thirteen priori expected factors. Analysis of the marginal effects revealed that effecting the use of the seven significant determinants: farmland size, per capita aggregate production, household size, gender of household head, use of fertilizer, use of pesticide/herbicide and education of household head, increase the likelihood of a household being food secure. Finally, interpretations of predicted conditional probabilities, following improvement of significant determinants, are given.
\end{abstract}

Keywords: Household; Food; Security; Logistic; Probability.

\section{Introduction}

The agricultural sector is the backbone of the Kenyan economy, making multifaceted contributions to the economy. It is responsible for about $24 \%$ of Gross Domestic Product, over 50\% of all domestic exports and employing about $70 \%$ of the labour force, see KNBS $(2007,2009)$. The performance of agriculture, however, in terms of feeding the country's population, which is growing at about 2.9 per cent per annum, is poor. Over 10 million Kenyan, of whom the majority reside in rural areas, are food insecure, KARI (2009). This is despite that $85.4 \%$ of all households in the rural Kenya are engaged in crop farming activities, see KNBS (2007, 2008). According to FAO (1996), food security occurs "when all people (at the individual, household, district, national, regional and global), at all 
times, have physical and economic access to sufficient, safe and nutritious food to meet their dietary needs and food preferences for an active and healthy life".

Recent estimates gives that at least $46.5 \%$ of the Kenyan population in Nyanza Province of the Lake Victoria basin live below the poverty line ${ }^{1}$, see KNBS (2008c). Food security studies and analyses are undertaken on regular basis and also in times of shocks. In the poverty reduction strategies under the Millennium Development Goals (MDGs), which started in the late 1990s in Tanzania and Uganda and in 2002 in Kenya, agriculture is considered one of the priority sectors. Agricultural crop production are included in the food balance sheet to help monitor deficit or surplus at the national level. However, these estimates naturally mask disparities in districts and other localized areas of high prevalence of food insecurity (Mwita et al, 2007). While efforts to ensure adequate food supplies at the national level are laudable, these efforts on their own cannot ensure food availability for households and individuals. As Sen (1981) argues, ensuring access to food, not merely increasing food supplies, should be regarded as a major pillar of food security. This assertion is borne out by empirical evidence that suggests that, even in times when countries experience famine, food supplies have been generally available, even in regions where large numbers of people died of starvation. The problem is that those who needed the food do not have the means to acquire it (Sen, 1986).

Much of the literature on food security focuses on developing and testing determinants of food insecurity at the household level (Maxwell, 1996). Mwita et al. (2007), investigated the relationship between the per capita calorific availability and household food security process and outcome indicators using some selected districts around the Lake Victoria Basin. It was found that, in general, (i) there exists a negative effect of the size of household on per capita calorific availability, (ii) the per capita calorific availability is better for women headed household than men headed, (iii) the per capita calorific availability has a positive relationship with commercial fertilizer, (iv) a positive relationship was observed with food production, and also (v) a positive relationship was observed with per capita income per year. There are many techniques to examine the association between variables such as correlation coefficient (Pearson or Spearman) and contingency tables (Chi-Squared). However, for purposes of quantification, regression models are best, Hoddinott (1999).

In this paper, random samples of 24 households were taken each from Bondo, Homa Bay and Kuria districts of the lake region of Kenya. Subsistence farming, pastoral and growing tobacco are the principal activity for Kuria ${ }^{2}$, while subsistence farming and fishing are main activities for Bondo ${ }^{3}$ and Homa

\footnotetext{
${ }^{1}$ Determined and based on the expenditure required to purchase a food basket that allows minimum nutritional requirements to be met (set at $2250 \mathrm{kcal}$ per adult equivalent per day) in addition to the cost of meeting other basic non-food needs.

${ }^{2}$ Proportion of households growing Maize (93\%), Casava (63.7\%), Sweet Potatoes $(30.2 \%)$ and Beans $(9.1 \%)$

${ }^{3}$ Proportion of households growing Maize (95.7\%), Sorghum (81.3\%), Beans (27.1\%) \& Casava (7.6\%)
} 
Bay $^{4}$, see KNBS (2007). This can be attributed mainly to medium-to-high rainfall and the proximity to the lake. These areas generally receive long rains around the months between March and May and short rains in around October and November. Consequently, during these months of long rains and the next main harvest season, few households have enough cereals to eat. Cattle, sheep, and goats are among the principal livestock kept by households in the study areas, KNBS (2007).

We use logistic regression to investigate the relationship between the priori determinants of households food security status within the framework of the definition of food security, i.e. food availability, food access and utilization. The effects on the food security status of households is investigated using thirteen factors which fall in any of the three food security pillars above. Estimates of probability of households being food secure given important determinants are obtained.

The following section gives the estimate of the likelihood of a household being food secure. Section 3 contains empirical results. Finally, section 4 concludes and makes recommendations.

\section{Methodology}

This section gives method for measuring food security status, expected determinants and their measurements, statistical methods and the model used to determine significant factors, and the estimation of the likelihood of a household being food secure.

\subsection{Measurement of Food Security Status}

Food security status is the dependent variable. It was measured in four stages. Firstly, food supply in kilograms at household level was determined by compiling a Food Balance Sheet for each of the 72 sampled households. Although main source of food is through own production, the following variables were used in the Balance Sheet as additions to or subtractions from own production of three main district food crops at household level: food purchases $(+)$, food received as aid $(+)$, post-harvest food losses (-), cereals used for seed (-), food marketed (-). The transformation was made from available food in kilograms to total available calories for each household by using the standard conversion factors, as they are in kinds, see FAO (2002). Secondly, the food available at household level calculated in step one was used to calculate calories available per person per day for each household. That is the Household calorific acquisition (per capita calories) was obtained by controlling time and household size. In that case, we took the total calories available in the household to be consumed, and divided by one hundred and fifty, with the latter being the average duration from planting up to harvest of all food available, and got the average Kilo calories per day. This

\footnotetext{
${ }^{4}$ Proportion of households growing Maize (95.3\%), Sorghum (38.5\%) Beans (33.5) and Sweet Potatoes (9.3\%)
} 
was then divided by the number of members of household to get the average kilo calories to be consumed per day per person in the household. Thirdly, 1683 kilo calories per person per day was used as a measure of calories required ${ }^{5}$ (i.e. demanded) to maintain body-weight and perform a sedentary light physical activity taking account of age and sex structure of the Kenya population, see KNBS (2008b). Lastly, we used the difference between calories available and required by a household to determine the food security status of a household. Households whose available per capita calories were found to be greater than their requirements, they were regarded as food secure and assigned a code of 1 , while households experiencing a calorie deficit, were regarded as food insecure and they were assigned a code of 0 .

\subsection{Other Variables}

(a) Per capita aggregate food production. This factor was expected to influence the food security status of households through the price effect. The higher per capital aggregate production, the lower the prices of food in markets. This was expected to influence the incomes of households whose income depend on the sale of food crops. Per capital aggregate production was computed by converting the output of different cereals in to their respective maize equivalent units.

(b) Household size. Increasing family size tends to exert more pressure on consumption than the labour it contributes to production on limited land that a household has. Thus a negative correlation between household size and food security was expected (Paddy (2003), Deaton and Paxson (1998)), as food requirements increase in relation to the number of persons in a household. In this study, the variable is measured by number of adult equivalent units in a household.

(c) Gender of household head. Survey of food deprivation by gender in Kenya show that male headed households had $52 \%$ prevalence of undernourished compared to $48 \%$ for female headed households, FIAK (2008) and $68 \%$ of male headed households are poor compared to $31.2 \%$ for female headed, KNBS (2008a). It was therefore expected that male headed households would be related positively with the food security status.

(d) Animals ownership. Ownership of Livestock, chicken, goats, sheep etc is a determinant of food security status. According to results in Mwita et al. (2007), the main reason for selling animals is buying food. Furthermore, animals (livestock) traction power enables households to cultivate bigger areas of land and agricultural operations timely, Govereh and Jayne (1999). Therefore, a positive relationship between animals ownership and food security was expected.

\footnotetext{
${ }^{5}$ According to KNBS (2008b), the average food dietary energy consumption at national level is $1800 \mathrm{kcal} / \mathrm{person} / \mathrm{day}$. The national minimum dietary energy requirement is $1683 \mathrm{kcal} / \mathrm{person} /$ day. FAO (1998) gives the medically recommended value of $2100 \mathrm{kcal}$ per adult equivalent per day, to enable an adult to live a healthy and moderately active life.
} 
(e) Fertilizer use. This was used as proxy for technology. Any farm input that augments agricultural productivity was expected to boost the overall production for consumption, which in terns, contributes towards attaining household food security, Brown (2004) and KNBS (2008b). Fertilizer use was measured on the basis of whether or not a household uses fertilizer i.e. a dummy variable was used.

(f) Herbicide/insecticide use. This is also a proxy for technology. Use of herbicides/insecticides for subsistence farming was expected to boost the production which interns contributes towards attaining household food security. This variable is measured as in the fertilizer use.

(g) Education. Educational attainment by the household head could lead to awareness of advantages of modernizing agriculture by means of technological inputs, enable them to read instructions on fertilizer packs and diversification of household incomes which, in turn, was expected to enhance households' food supply. Households with no educated heads were assigned a value of 0 while those led by educated heads (at least primary school) took a value of 1 .

(h) Farmland size. Food production was expected to be increased extensively through expansion of areas under cultivation. Hence, for subsistence farming, land size was expected to influence households' food security. The size of farmland owned by a household was determined by summing the fragmented plots, and converting to hectares.

(i) Fertility status of the farmland. This measured the farmers' perception of the fertility of their farmland. Households indicated whether they consider their land as fertile or poor, on average. Fertile farmland boosts crop production. Sah (2002) found that a decline in soil fertility negatively affects food security. It was therefore expected that farmland fertility would affect food security status of households positively.

(j) Age of the household head. Older people have relatively richer experiences of the social and physical environments as well as greater experience of subsistence farming activities, Hofferth (2003). They also have better access to farmland than younger heads, Obamiro et al (2003). Age of household head was therefore expected to influence food security of a household. Age was measured in years.

(k) Diversification of sources of income. This is a survival strategy which allows household heads to reduce the risk of starvation for themselves and their families during periods of food insecurity (Devereux 1993), Maxwell and Frankenburger, (1992)). Households may diversify their incomes by selling firewood, working on farms as daily labourers, and selling crafts. In this study participation in off farm and non-farm activities was measured by whether or not a household was engaged in those activities i.e. a dummy variable was used. A household who engaged in off-farm and non-farm activities was assigned a value of one and a household that did not engage in those activities took a value of zero. 
(I) Per capita income in Kenya Shillings (KSh). The net income obtained by a household was divided by the number of household members to obtain the per capita income for the whole year. It was expected that food security status with per capita income would be positively correlated.

(m) Dietary diversity. This is a measure of nutritional status. It is measured by the number of different foods or food groups consumed over a given reference period. A weighted sum is used to stand for dietary diversity. The index of diversity has been found to be correlated with per capita calorific availability, Hoddinott (1999). Hence in this study the dietary diversity was expected to be positively correlated with food security.

\subsection{Data sources}

The data used in this study was obtained from raw data on Household Demography, Food (cereal) Production, Food Aid/ Assistance, Source of Income, Household and Animal Assets, Household food expenditure, Access to Services, Food Consumption, Nutritional status and dietary diversity collected during first year work of the project entitled "Mathematical Techniques for Food Crops Balance Sheet and Food Security Indicators in Lake Victoria Water Shed", see Mwita et al. (2007). A total of 24 households in each of the three districts (Bondo, Homa Bay and Kuria) in Kenya were surveyed using structured questionnaire, interview sessions, focus group discussion and observation. A separate survey was conducted on the same households to provide the data for food balance sheet. The questionnaire included further questions on cereal production, aid, post-harvest losses, cereal used for seed and cereal marketed.

A total of thirteen explanatory variables were used: six measured as quantitative and seven as qualitative variables. However, seven were identified to be major determinants of food security. These include per capita aggregate production, fertilizer use, pesticides/herbicides use, farmland size, household size, gender of household head and education of household head.

\subsection{The model}

We model the food security status of households using logistic regression model whose function is given as

$$
P_{i}=E\left(Y_{i}=1 \mid X_{i, 1}, X_{i, 2}, \ldots, X_{i, k}\right)=\frac{1}{1+e^{-\left(\beta_{0}+\sum_{j=1}^{k} \beta_{j} X_{i, j}\right)}}, i=1,2, \ldots, n
$$

where: $P_{i}$ stands for the probability of household $i$ being food secure, $Y_{i}$ is the observed food security status of household $i, \quad X_{i, j}, j=1,2, \ldots, k$ are factors determining the food security status for household $i$ and $k+1$ are the number of parameters to be estimated. The variables in this case are; 
$Y_{i} \quad$ Food Security Status for household $i$ ( $0=$ insecure and $1=$ secure)

$X_{i, 1} \quad$ Household size (number)

$X_{i, 2} \quad$ Gender of the $\mathrm{HH}$ head ( $0=$ male and $1=$ female)

$X_{i, 3} \quad$ Farmland size (hectare)

$X_{i, 4} \quad$ Fertilizer use $(0=$ no and $1=y e s)$

$X_{i, 5} \quad$ Per capita aggregate production (number of kilograms)

$X_{i, 6} \quad$ Per capita income (amount of money in KSh.)

$X_{i, 7} \quad$ Dietary diversity (weighted sum)

$X_{i, 8} \quad$ Education ( $0=$ no education and $1=$ at least primary school)

$X_{i, 9} \quad$ Pesticide/herbicide use ( $0=$ no and 1 =yes)

$X_{i, 10} \quad$ Fertility status of farmland (0=poor, $1=$ fertile)

$X_{i, 11} \quad$ Animal ownership ( $0=$ no animal and $1=$ at least one)

$\begin{array}{ll}X_{i, 12} & \text { Diversification of sources of income }(0=\text { no diversification and } \\ 1=\text { diversifies })\end{array}$

$X_{i, 13} \quad$ Age of household head (years)

Note that the extent of household food security can be found using the level of probability in (1).

For simplicity, let $Z_{i}=\beta_{0}+\sum_{j=1}^{k} \beta_{j} X_{i, j}$. Then, the logistic function, can then be written to give the probability of household $i$ being secure as:

$$
P_{i}=\frac{1}{1+e^{-Z_{i}}}, \quad i=1,2, \ldots, n
$$

where it is assumed that $Z_{i}$ represents the exposure to some set of factors given above. The probability of a household $i$ being food insecure can be written as

$$
1-P_{i}=\frac{1}{1+e^{Z_{i}}}, \quad i=1,2, \ldots, n
$$

The odds of household $i$ is therefore obtained by dividing (2) by (3) as

$$
\frac{P_{i}}{1-P_{i}}=\frac{1+e^{Z_{i}}}{1+e^{-Z_{i}}}=e^{Z_{i}}, \quad i=1,2, \ldots, n
$$


We offset the loss of symmetry inherent in the transformation of probability to odds by taking natural logarithm of equation (4), giving rise to the following logit function, in terms of $X_{i, j}$,

$$
\log i t\left(P_{i}\right)=\operatorname{In}\left(\frac{P_{i}}{1-P_{i}}\right)=\beta_{0}+\sum_{j=1}^{k} \beta_{j} X_{i, j}
$$

Note that this is a linear function in $X_{i, j}, j=1,2, \ldots, k$. Therefore, we can use the function in (5) to write a multiple linear model with a logistic error $\varepsilon_{i}$, see Cramer (1991, section 2.3$)$, as,

$$
\tilde{Y}_{i}=\beta_{0}+\sum_{j=1}^{k} \beta_{j} X_{i, j}+\varepsilon_{i}, \quad i=1,2, \ldots, n, j=1,2, \ldots, k
$$

The error $\varepsilon_{i}$ is assumed independent and identically distributed with mean zero and unit scale. In vector/matrix form, (6) can be expressed as

$$
\tilde{Y}=\left[\begin{array}{c}
\tilde{Y}_{1} \\
\tilde{Y}_{2} \\
\cdot \\
\cdot \\
\cdot \\
\tilde{Y}_{n}
\end{array}\right]=\left[\begin{array}{ccccccc}
1 & X_{1,1} & X_{1,2} & \cdot & \cdot & \cdot & X_{1, k} \\
1 & X_{2,1} & X_{2,2} & \cdot & \cdot & \cdot & X_{2, k} \\
\cdot & \cdot & \cdot & \cdot & \cdot & \cdot & \cdot \\
\cdot & \cdot & \cdot & \cdot & \cdot & \cdot & \cdot \\
\cdot & \cdot & \cdot & \cdot & \cdot & \cdot & \cdot \\
1 & X_{n, 1} & X_{n, 2} & \cdot & \cdot & \cdot & X_{n, k}
\end{array}\right]\left[\begin{array}{c}
\beta_{0} \\
\beta_{1} \\
\cdot \\
\cdot \\
\cdot \\
\beta_{k}
\end{array}\right]+\left[\begin{array}{c}
\varepsilon_{1} \\
\varepsilon_{2} \\
\cdot \\
\cdot \\
\cdot \\
\varepsilon_{n}
\end{array}\right]=\underset{n \times k}{\beta} \underset{k \times 1}{\beta} \underset{n \times 1}{\varepsilon}
$$

and $n=72$. This can be considered as a generalized linear regression model. The columns contain $n$ observations for each of the $k(k=13)$ variables in the model. The rows represent households (or trials). We estimate the unknown parameters $\beta_{j}, j=0,1,2, \ldots, k$ by maximum likelihood method. Such a method gives estimators that are consistent and asymptotically normal, see e.g. Gourieroux and Monfort (1981), Amemiya (1985) and Christensen, R. (1997).

The estimator of $Z_{i}$ is then

$$
\hat{Z}_{i}=\hat{\tilde{Y}}_{i}=\hat{\beta}_{0}+\sum_{j=1}^{k^{\prime}} \hat{\beta}_{j} X_{i, j}, \quad i=1,2, \ldots, n
$$

where $k^{\prime} \leq k$ is the number of significant parameters, and $\hat{P}_{i}, \hat{\tilde{Y}}_{i}, \hat{\beta}_{0}$ and $\hat{\beta}_{j}$ are estimates of $P_{i}, \tilde{Y}_{i}, \beta_{0}$ and $\beta_{j}$ respectively. The predicted conditional probability of household $i$ being food secure given significant factors (determinants) is

$$
\hat{P}_{i}=\frac{1}{1+e^{-\left(\hat{\beta}_{0}+\sum_{j=1}^{k^{\prime}} \hat{\beta}_{j} X_{i, j}\right)}}, i=1,2, \ldots, n
$$


We obtain the marginal effect for a determinant in the following way:

(i) Choose a variable, $X_{i, j}$, from among significant determinants, with $j=1,2, \ldots, k^{\prime}$. In the current case, determinants are both quantitative and qualitative.

(ii) Fix other determinants at sample mean ${ }^{6}$ of insecure households, if they are quantitative. If they are qualitative (in this case binary), fix them at 0 .

(iii) Obtain the marginal effect of the determinant of interest, $X_{i, j}$, by getting the difference between predicted probabilities given by equation (8), when the determinant changes from one value to another, while other determinants are held constant. In our case, we consider a unit change from the sample mean under insecure households for quantitative determinant or from 0 to 1 for qualitative.

The following is an illustration using only three determinants, $X_{i, 1}, X_{i, 3}$ and $X_{i, 4}$, for simplicity. It is straightforward to generalize. Assume their fixed values are correspondingly $\bar{x}_{1}, \bar{x}_{3}$ and 0 . The difference in predicted probabilities when $X_{i, 1}$ changes from the sample mean under food insecure households $\left(\bar{x}_{1}\right)$ to the mean $\left(\bar{x}_{1}^{*}\right)$, gives an expression for the marginal effect for $X_{i, 1}$ as,

$$
\frac{1}{1+e^{-\left(\hat{\beta}_{0}+\hat{\beta}_{1} \bar{x}_{1}^{*}+\hat{\beta}_{3} \bar{x}_{3}+\hat{\beta}_{4} \cdot 0\right)}}-\frac{1}{1+e^{-\left(\hat{\beta}_{0}+\hat{\beta}_{1} \bar{x}_{1}+\hat{\beta}_{3} \bar{x}_{3}+\hat{\beta}_{4} \cdot 0\right)}}
$$

The "marginal" effects of the discrete factors are calculated by taking the difference of the probabilities estimated when value of the factor is set to 0 and 1 $\left(X_{i,}=0, X_{i, .}=1\right)$. The marginal effect for the indicator variable $X_{i, 4}$ is therefore obtained as

$$
\frac{1}{1+e^{-\left(\hat{\beta}_{0}+\hat{\beta}_{1} \bar{x}_{1}+\hat{\beta}_{3} \bar{x}_{3}+\hat{\beta}_{4} \cdot 1\right.}}-\frac{1}{1+e^{-\left(\hat{\beta}_{0}+\hat{\beta}_{1} \bar{x}_{1}+\hat{\beta}_{3} \bar{x}_{3}+\hat{\beta}_{4} \cdot 0\right.}}
$$

Other approaches for calculating marginal effects exist. For example calculating marginal derivative of $P_{i}$ with respect to $X_{i, j}$ gives an estimated marginal effect of a continuous individual determinant on household food security as,

$$
\frac{\partial \hat{P}_{i}}{\partial X_{i, j}}=\hat{P}_{i}\left(1-\hat{P}_{i}\right) \hat{\beta}_{j}
$$

The is approach only makes use of continuous variables, effectively. So the former approach was adopted in this work.

\section{Empirical Results}

We fitted the model on the proposed determinants of household food security status using the maximum likelihood method. The $\mathrm{R}$ Statistical software was used in this case. The confidence intervals, at $5 \%$ level of significance, of the

\footnotetext{
${ }^{6}$ The factors are usually set to their sample mean values. In the current case, we chose the mean at food insecure households.
} 
estimates were used to test the significance of parameter estimates. The likelihood ratio Chi-Square test, Oezdemir and Eyduran (2005), was used to test the significance of the model, while Pesaran-Timmermann test, Pesaran and Timmerman (1992), was used to test for the prediction efficiency. The results are shown in Table 1. The parameter estimates and their corresponding confidence interval at $5 \%$. The averages under both secure and insecure households for respective factors are also given. For qualitative factors, percentages were obtained with the value of variables set to 1 . Step by step elimination of insignificant variables reduced the number of significant variables to seven. The average farmland size, average per capita aggregate production, percentage of fertilizer users, percentage of pesticide users, percentage of household with female as head, percentage of educated household heads are all of food secure households and are higher than corresponding food insecure households on average. On the other hand, household size is higher among food insecure households than among food secure households. These results confirm the findings of the literature and our expectation regarding the relationship between food security status and the major determinants of food security.

From Table 2, the log likelihood value of 38.67 with $\mathrm{P}<0.001$ indicates that at least one of parameters of the determinant of food security shown in equation (1) is significant. With regard to the predictive efficacy of the model, out of the 72 sampled households included in the model, 67 (93.06\%) are correctly predicted. According to the Pesaran-Timmermann test statistic, a significant association exists between the observed and the models' prediction of a household food security status.

Table 1: Parameter Estimates of the Logistic Regression

\begin{tabular}{|l|l|l|l|}
\hline Variable & \multicolumn{1}{|c|}{$\begin{array}{c}\text { Coefficient } \\
(95 \% \text { Confidence Interval) }\end{array}$} & $\begin{array}{c}\text { Food } \\
\text { Secure }\end{array}$ & $\begin{array}{c}\text { Food } \\
\text { Insecure }\end{array}$ \\
\hline Constant & $3.685(2.982,4.085)$ & - & - \\
\hline Farmland Size (ha) & $0.084(0.012,0.195)$ & 2.34 & 1.56 \\
\hline $\begin{array}{l}\text { Per capita aggregate } \\
\text { Production (Kg) }\end{array}$ & $0.006(0.002,0.009)$ & 149.86 & 70.34 \\
\hline Gender of HH head (\%) & $0.334(0.045,0.665)$ & 54.37 & 44.28 \\
\hline Fertilizer use (\%) & $0.256(0.107,0.578)$ & 79.78 & 50.65 \\
\hline Pesticides/herbicides use (\%) & $0.344(0.035,1.766)$ & 70.55 & 55.45 \\
\hline Household size (number) & $-1.172(-1.942,-0.345)$ & 4.5 & 5.8 \\
\hline Education of HH head (\%) & $0.296(0.045,0.542)$ & 62.34 & 34 \\
\hline Per capita income (amount) & $0.139(-0.075,1.237)$ & 58,940 & 33,780 \\
\hline $\begin{array}{l}\text { Dietary Diversity (weighted } \\
\text { sum) }\end{array}$ & $0.145(-0.056,0.339)$ & 33.75 & 20.55 \\
\hline Fertility status of farmland & $0.096(-0.002,0.167)$ & 1.82 & 1.45 \\
\hline Animal ownership (\%) & $0.104(-0.011,0.234)$ & 24.78 & 24.67 \\
\hline $\begin{array}{l}\text { Diversification of sources of } \\
\text { income (\%) }\end{array}$ & $0.110(-0.001,0.178)$ & 26.87 & 24.77 \\
\hline Age of household head & $0.016(-0.002,0.124)$ & 37 & 26.5 \\
\hline
\end{tabular}


Table 2: Significance and Efficiency

\begin{tabular}{|l|l|l|}
\hline & Value & P-Value \\
\hline The Pesaran-Timmermann test statistic & 6.4229 & $<0.001$ \\
\hline Log likelihood value & 38.67 & $<0.001$ \\
\hline Percent of correct prediction & 0.9063 & \\
\hline
\end{tabular}

\subsection{Marginal Effects and Interpretation}

The marginal effects of a unit change in the significant quantitative variables, computed at sample means, on the probability of food security were estimated. Tables 3 and 4 give results on the marginal effects of quantitative and qualitative variables respectively, see equations (9) and (10) for computation.

\section{(a) Quantitative Variables}

\section{Farm land size}

From Tables 1, farmland size is positively and significantly related to the status of a household being food secure. From Table 3, the marginal effect of a unit change in farm size, computed at sample mean of holding size, on the probability of food security is 0.0058 . This means that the probability of a household to be food secure will increase by 0.0058 for one hectare increase in farmland size.

\section{Per capita production}

This factor was found to have significant positive relationship with food security status. A unit increase in kilogram, computed at sample mean, will increase the probability of a household food security by $0.04 \%$.

\section{Household size}

Size of household has a negative significant relationship with the probability of food security. Table 3 shows that the probability of being food secure, calculated at average family size of sampled households, decreases with an increase in family size. Each additional member of the household will decrease the probability of a household being food secure by about $4.8 \%$.

Table 3: Marginal Effects for Significant Quantitative Determinants

\begin{tabular}{|l|l|}
\hline Determinants & "Marginal Effects \\
\hline Farmland size & 0.0058 \\
\hline Per capita aggregate production & 0.0004 \\
\hline Household size & -0.0484 \\
\hline
\end{tabular}




\section{(b) Qualitative Variables}

\section{Fertilizer application}

Fertilizer use was found to have a significant impact on household food security. A significant positive relationship was found between fertilizer usage and the probability of a household being food secure, see Table 1 . This means that the likelihood of food security increases with household use of fertilizer in the farm. In other words, fertilizer users are more likely to be food secure than non-users. From Table 4, a unit increase in fertilizer use defined by the shift from nonfertilizer user $\left(X_{i, .}=0\right)$ to fertilizer user $\left(X_{i,}=1\right)$ increases the probability of food security by about $1.9 \%$.

Table 4: Change in Probabilities between $X_{i, .}=0$ and $X_{i, .}=1$ for the Significant Qualitative Determinants

\begin{tabular}{|l|l|}
\hline Determinants & Change in Probabilities \\
\hline Gender of HH head & \\
\hline Male & 0.0257 \\
\hline Female & \\
\hline Fertilizer use & \multirow{2}{*}{0.0190} \\
\hline Non users & \\
\hline Users & \\
\hline Education & 0.0224 \\
\hline No ducation & \\
\hline Completed at least primary school & \\
\hline Pesticide/Herbicide Use & 0.0266 \\
\hline Non users & \\
\hline Users &
\end{tabular}

\section{Education}

Education and household food security were found to have significant positive relationship. This indicates that households with educated household heads are more likely to be food secure than those headed by uneducated household heads. From Table 4, completion of primary school defined by the shift in educational level from no education $\left(X_{i, .}=0\right)$ to at least primary school $\left(X_{i, .}=1\right)$ results in increase in probability of a household being food secure about $2.2 \%$.

\section{Gender of household head}

This variable is positively and significantly related to the household food security status. From Table 4, a household with a female as head is more likely to be food secure than a male headed household by about $2.6 \%$. 


\section{Pesticide/Herbicide use}

Use of pesticide/herbicide increases the likelihood of a household becoming food secure by probability of about $2.7 \%$.

\subsection{Impact of Major Determinants on Food Security Status}

The impact of significant factors was assessed through levels of change in the predicted conditional probability of household being food secure following improvement in any of the significant factor. Predictions were done with reference to a base group of households representing food insecure households. The results are reported in Table 5. The base group represents food insecure households with an average farm land size of 1.56 ha, per capita aggregate production of $70.34 \mathrm{~kg}$, and average household size of 5.8 members. In addition, the dummy variables for gender of household head, fertilizer application, pesticide/herbicide application and educational attainment were set to zero.

\section{Table 5: Impact of Determinants on the Probability of Household Food Security}

\begin{tabular}{|l|l|}
\hline Variable & $\begin{array}{c}\text { Predicted } \\
\text { Probabilities }\end{array}$ \\
\hline Base & 0.0718 \\
\hline Increase of farmland by one hector & 0.0776 \\
\hline Increase in Per capita aggregate production by 70Kg & 0.1053 \\
\hline If the gender of HH head is female & 0.0975 \\
\hline If a household adopts fertilizer usage & 0.0908 \\
\hline If a household adopts Pesticides/herbicides usage & 0.0984 \\
\hline If a household size is reduced by 1 & 0.1998 \\
\hline $\begin{array}{l}\text { If education level of HH head improves to at least } \\
\text { primary school }\end{array}$ & 0.0942 \\
\hline
\end{tabular}

From Table 5, the conditional probability of a household being food secure for the base group of households is about 0.072. This means that, out of 100 households with similar characteristics as the base group, about 7 will be food secure. If a thousand households with characteristics similar to that of the base group of households apply fertilizer, the number of food secure households will increase to 9 from 7. A $70 \mathrm{~kg}$ increase in the per capita aggregate production (in maize equivalent) for the base group of household will increase the number of food secure households from 7 to about 11. Improvement in the education of household heads of the base group of households will increase the number of food secure households to 9 in 100. Furthermore, an increase in the average farmland size of the base group of households by one hectare results in an increase in the number of food secure households from 7 to about 8 . A decrease in the average household size of farmers from 5.8 to 4.8 will lead to an increase in the number of secure household from 7 to 20 . 


\section{Conclusion}

Food balance sheet has been used with the logistic regression model to predict the status of households food security. Significant causes of household food insecurity in the three districts (Bondo, Homa Bay and Kuria) of the Kenyan part of Lake Victoria region have been determined. These factors are farmland size, per capita aggregate production, gender of household head, use of fertilizer, use of pesticide/herbicide, household size and education. The estimates of marginal effects, computed at sample means using significant quantitative factors, show that a unit change in the latter improves the predicted likelihood of a household being food secure in the region.

Impact assessment conducted with reference to food insecure households showed that an increase in farmland size, increase in per capita aggregate production, female as household head, decrease in household size, usage of fertilizer, usage of pesticide/herbicide, and improvement in education, all have the potential to increase the number of food secure households in the three districts. For example, reducing the size of household members in the food insecure households will increase the number of food secure households by about $12 \%$; Availing fertilizer to food insecure households for usage, will increase the likelihood for food security by $1.9 \%$. Improving the education of food insecure household heads will increase the likelihood of a household being food secure by $2.2 \%$

To increase the number of food secure households in the region, it is recommended that: Fertilizer and pesticide/herbicide should be made accessible to household farmers; households should be encouraged to exercise family planning to reduce the number of household members; agricultural institutions should intensify field extensions to enable household farmers adopt new methods and technology for efficient use of farmlands; and free primary school program in Kenya should continue and learning be made compulsory to all school going age children, and the adult education system fostered in the region to reduce the number of illiterate household heads.

\section{Acknowledgement}

The authors acknowledge the Inter-University Council for East Africa, under the Lake Victoria Research Initiative (VicRes), for providing financial support.

\section{References}

1. Amemiya, T. (1985). Advanced Econometrics, Harvard University Press, Cambridge.

2. Brown, L. R. (2004). World Food Security Deteriorating: Food Crunch in 2005 Now Likely. Washington DC: Earth Policy institute, http://www.earthpolicy.org/updates/update40.htm.

3. Christensen, R. (1997). Log-linear Models and Logistic Regression, Springer Text in Statistics, 2nd Edn, Springer, New York. 
4. Cramer, J.S. (1991). The LOGIT model: an Introduction for Economists, Edward Arnold, London.

5. Devereux, S (1993). Goats Before Ploughs: Dilemmas of Household Response Sequencing during Food Shortages. Institute for Development Studies Bulletin 24, 29-43.

6. Food and Agricultural Organization (FAO) (1996). Rome Declaration on World Food Security and World Food. Rome, Italy. Available at www.fao.org.

7. Food and Agricultural Organization (FAO) (1998). Crop and food supply assessment mission to Ethopia. FAO Global Information and Early Warning System on Food and Agriculture. World Food Program. Rome, Italy. http://www.fao.org/countryprofiles/index.asp?lang=en\&iso3=ETH\&paia=3

8. Food and Agricultural Organization (FAO) (2001). Crop and food supply assessment mission to Kenya. FAO Global Information and Early Warning System on Food and Agriculture. World Food Program. Rome, Italy.

9. Food and Agriculture Organization (FAO) (2002). Food Energy-Methods of Analysis and Conversion Factors. FAO Food and Nutrition paper 77. Report of a Technical Workshop Rome, 3-6 December 2002. Available at $\mathrm{ftp}: / / f t p . f a o . o r g / d o c r e p / f a o / 006 / y 5022 e / y 5022 e 00 . p d f$

10. Gourieroux, C. and Monfort, A. (1981). Asymptotic Properties of the Maximum Likelihood Estimator in Dichotomous Logit Models, Journal of Econometrics, 17, 83-97.

11. Govereh, J. and Jayne, T.S. (1999). Policy Synthesis: Effects of Cash Crop Production on Food Crop Productivity in Zimbabwe: Synergies Or Trade-Offs? USAID - Africa Bureau, Office of Sustainable Development No 40.

12. Hoddinott, T. (1999). Operationalizing household security and development strategies, International Food Policy Research Institute, Technical Guideline, No. 1.Wasshington, DC.

13. Hofferth, S. L. (2003). Persistence and Change in the Food Security of Families with Children, 1997-1999. Department of Family Studies, University of Maryland. Available online: http://www.findarticles.com/ p/articles/mi_m1309/is_3_40/ai_111027115

14. Kenya Agricultural Research Institute (KARI) (2009). Policy Responses to Food Crisis in Kenya. Food Security Portal. http://www.foodsecurityportal.org/kenya

15. Kenya National Bureau of Statistics (KNBS) (2007). Basic Report: Kenya Integrated Household Budget Survey-2005/06. A publication of the Kenya National Bureau of statistics. ISBN: 9966-767-X.

16. Kenya National Bureau of Statistics (KNBS) (2008a). Well-Being in Kenya: A socio-Economic Profile. A Publication of the Kenya National Bureau of Statistics. ISBN: 9966-767-13-4. 
17. Kenya National Bureau of Statistics (KNBS) (2008b). Food Insecurity Assessment in Kenya, Based on Kenya Integrated Household Basic Survey, 2005/06. A publication of the Kenya National Bureau of Statistics.

18. Kenya National Bureau of Statistics (KNBS) (2008c). Constituency Report on Well-Being in Kenya Based on the Kenya Integrated Household Budget Survey-2005/06. A Publication of the Kenya National Bureau of Statistics. ISBN: 966-767-10-X.

19. Maxwell, S. (1996). Food security: A post modern perspective. Food Policy. 21(2) 155-170.

20. Maxwell, S. and Frankenberger, T. (1992). Household Food Security, Concepts, Indicators and Measurements: a Technical Review. UNICEF/IFAD, New York/Rome.

21. Mwita, P., Masanja, V., Muyanja, C. and Odhiambo, R. (2007). Mathematical Techniques for Food Crops Balance Sheet and Food Security Indicators in Lake Victoria Water Shed. Technical Report. InterUniversity Council of East Africa.

22. Obamiro, E.O., Doppler, W., Kormawa, P. M. (2003). Pillars of Food Security in Rural Areas of Nigeria. Food Africa, Internet Forum 31 March 11 April, Internet Paper accepted for the Food Security Theme. Available online http://foodafrica.nri.org/security/internetpapers/ObamiroEunice.pdf

23. Oezdemir, T. and Eyduran, E. (2005). Comparison of Chi-Square and Likelihood Ratio Chi-Square Tests: Power of Test, Journal of Applied Sciences Research, 1(2), 242-244.

24. Paddy, F. (2003). Gender differentials in land ownership and their impact on household food security: a case study of Masaka district. Master thesis. Uganda. Available on: http://www.troz.uni-hohenheim.de/research/ Thesis/MScAES/Paddy.pdf

25. Pesaran, H. M. and Timmermann, A. (1992). A Simple Nonparametric Test of Predictive Performance, Journal of Business and Economic Statistics, 10(4), 561-565.

26. Sah, R. P. (2002). Sustainable Livelihoods and Poverty Alleviation: Case Study in Improving Food Security and Livelihood of Mountain People through Development of Agriculture. A paper presented at the International Seminar on Mountains (ISM), Kathmandu, Nepal, March 6-8, 2002. Agriculture Research Station, Kaski, Nepal.

27. Sen, A. (1981). Poverty and famines. Oxford: Clarendon Press.

28. Sen, A. (1986). Food, economics, and entitlements. Lloyd's Bank Review. 160: 1-20. 